\title{
Spontaneous periodic hypothermia with lipoma of the corpus callosum
}

\author{
GD SUMMERS, AC YOUNG, RA LitTle, HB STONER, WSTC FORBES, \\ RAC JONES \\ From the Department of Neurosciences, Salford Royal Hospital and the MRC Trauma Unit, University of \\ Manchester
}

SUMmARY A patient with spontaneous periodic hypothermia who had both a lipoma and agenesis of the corpus callosum is described. Spontaneous periodic hypothermia associated with corpus callosum abnormalities is a distinct entity and although the mechanism underlying the hypothermic episodes is unexplained, the term "diencephalic autonomic epilepsy" does not seem appropriate.

Spontaneous periodic hypothermia is a rare condition in which episodes of severe hypothermia are precipitated by profuse sweating. Penfield ${ }^{1}$ introduced the term "diencephalic autonomic epilepsy" to describe a patient with attacks of hypothermia, headache, hiccough, sweating and salivation in a terminal illness from a third ventricular tumour. This term has been applied to patients with spontaneous periodic hypothermia. However, only 12 cases have been described (table) and a stereotyped syndrome emerges differing substantially from Penfield's patient. This syndrome is a chronic one, often beginning in childhood or early adult life and progressing very slowly. Agenesis of the corpus callosum is almost the hallmark of the condition, being found in seven out of nine patients who had adequate investigations. The association of callosal agenesis and periodic hypothermia has been termed "Shapiro's syndrome". ${ }^{6}$ We report a patient with this syndrome in whom a lipoma and agenesis of the corpus callosum were demonstrated by a computed tomographic scan (CT scan).

\section{Case history}

A 44-year-old unmarried man was admitted in January 1980 for the investigation of recurrent episodes of stupor associated with profuse sweating and hypothermia. Sweating attacks started in his teens and from 1969 there were numerous admissions to general and psychiatric hospitals. During three years in this region he had seven hospital admissions because of hypothermia. Admissions were mainly in winter and recovery took 2-6 weeks.

Address for reprint requests: AC Young, Salford Royal Hospital, Chapel Street, Salford M60 9EP, UK.

Received 3 June 1981. Accepted 7 August 1981
Profuse sweating for several days had been noted during one of them.

When two years old he had sustained a fractured skull in a road traffic accident. His physical development was normal but he was mentally slow and had attended a special school. He had worked in a furniture factory for nearly 20 years, eventually being forced to retire by ill health. For at least 6 years he had major seizures treated with Phenytoin $100 \mathrm{mg}$ twice daily. On examination he was thin with a normal male distribution of body hair. He was alert and orientated but below average intelligence (WAIS IQ = 75). He had mild dysarthria with exaggerated reflexes in the left arm and bilateral extensor plantar responses. After three weeks in hospital, during which he was well and ambulant with an oral temperature between $35.0^{\circ} \mathrm{C}$ and $36.5^{\circ} \mathrm{C}$, blood pressure $120 / 80$ $\mathrm{mmHg}$ and pulse rate 60 per minute, he suddenly developed profuse sweating accompanied by cutaneous vasodilatation which affected the whole body surface. He complained of feeling hot and after 2 hours continuous sweating his oral temperature was $31.0^{\circ} \mathrm{C}$. Any rise in body temperature provoked further attacks of sweating lasting 30 minutes to several hours and with each attack the rectal temperature fell, often as low as $29 \cdot 5^{\circ} \mathrm{C}$ (fig 1 ). Two days after the onset of sweating the patient became lethargic and withdrawn. His dysarthria increased, he had marked truncal ataxia and flapping tremor of the outstretched hands. After 4 days he was unresponsive and incontinent. Systolic blood pressure varied between $75-100 \mathrm{mmHg}$ with marked bradycardia, sometimes as slow as 40 per minute. The ECG showed typical J-waves. Five days later his body temperature returned abruptly to his normal level. His physical and mental state recovered after two days. Seven days later he had a similar sudden episode of sweating and hypothermia which lasted 8 days. His hospital course was marked by alternating periods of relative normality and sweating with hypothermia. Shivering was never seen. Several major and left sided focal motor attacks occurred during 


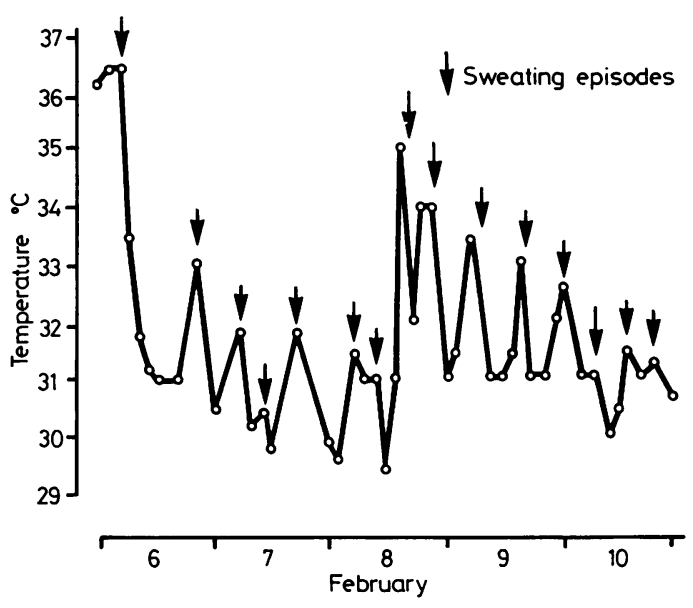

Fig 1 showing that episcdes of severe sweating coincided with each rise in body temperature producing a set-point which is lower than normal.

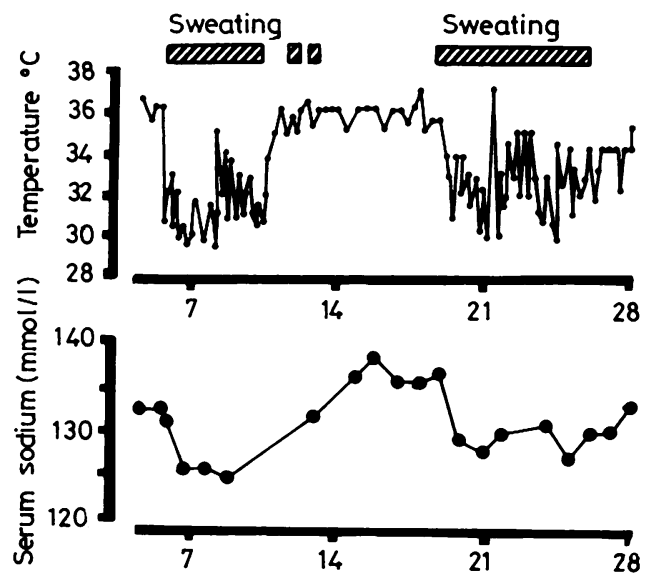

Fig 2 (continued in next column)

the hypothermic periods. When cellulitis developed in the left buttock the temperature rose to $40^{\circ} \mathrm{C}$, but he did not sweat.

Investigations revealed a normozhromic, normozytic anaemia with a haemoglobin between 8 and $12 \mathrm{~g} / \mathrm{dl}$. There was an intermittent leucopenia $\left(2 \times 10^{9} / 1\right)$ and a mild thrombocytopenia $\left(137 \times 10^{9} / 1\right)$. Serum iron, total iron binding capacity, folate and B12 levels were normal and marrow aspiration showed dyserythropoiesis similar to that seen in the anaemia of chronic disorders. Sweating episodes were associated with a marked hyponatraemia (serum sodium 124-126 mmol/l) and a fall in serum osmolality. There was a corresponding fall in urine osmolality, urine sodium, urine volume and creatinine clearance with improvement as the sweating subsided (fig 2). Liver enzymes rose in parallel with the severity and
Fig 2 (continued)
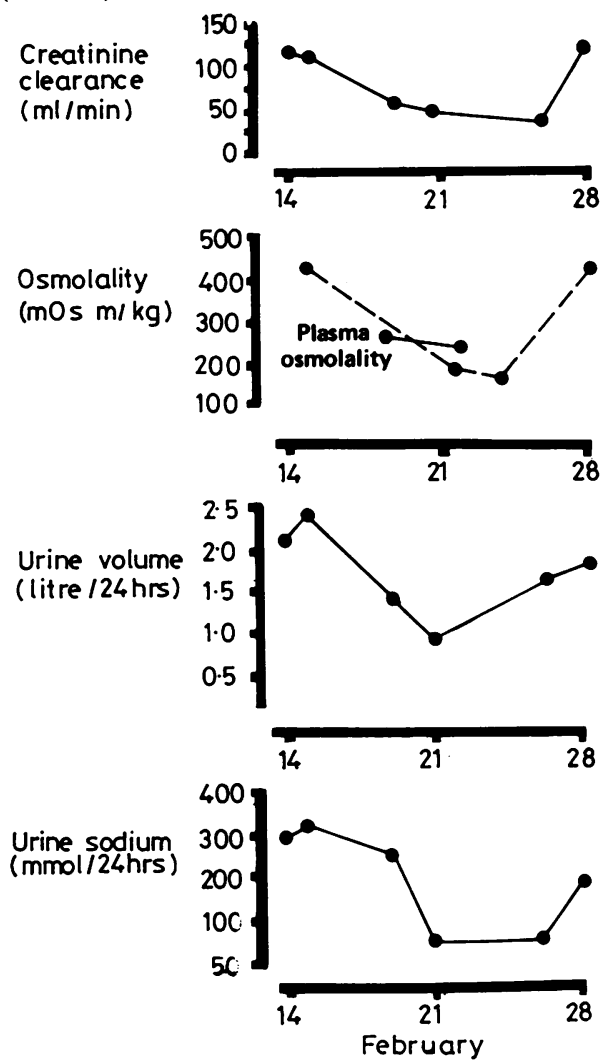

Fig 2 showing changes in the serum and urine parameters during episodes of hypotherniia.

length of the hypothermic episode. Before one episode of hypothermia, some additional metabolic and physiological tests were carried out. Mean skin and core temperatures were already lower than normal, $30 \cdot 1^{\circ} \mathrm{C}$ and $35 \cdot 2^{\circ} \mathrm{C}$ respectively, giving a whole body temperature of $32.5^{\circ} \mathrm{C}$. The resting energy expenditure was 34.6 kcal m $\mathrm{m}^{-2} \mathrm{~h}^{-1}$ which was $4.4 \%$ below his predicted rate but was higher than that rate corrected for the lower body temperature. Tests of autonomic cardiac control showed that his pulse rate was not altered by such stimuli as deep inspiration, a head up tilt or a Valsalva manoeuvre. At the time of these tests the plasma glucose, lactate and insulin concentrations were $4.4 \mathrm{mmol} / 1,1.36 \mathrm{mmol} / 1$ and $22 \mu \mathrm{U} / \mathrm{ml}$ respectively. Later while the temperature was falling these values were $5.72 \mathrm{mmol} / \mathrm{l}, 2 \cdot 10 \mathrm{mmol} / \mathrm{l}$ and $27 \mu \mathrm{U} / \mathrm{ml}$ (expected changes). An oral glucose tolerance test between episodes was within normal limits. The urinary normetanephrine and 5-hydroxyindole acetic acid concentrations were repeatedly rormal. There was no evidence of abnormality of the hypothalamic pituitary axis as judged by the results of TRH and FSH/LHRH stimulation tests and there was a normal circadian rhythm of the plasma cortisol. 
Table Reported cases of spontaneous periodic hypothermia

\begin{tabular}{|c|c|c|c|c|c|}
\hline Author(s) & Lesion & $\operatorname{Sex}$ & $\begin{array}{l}\text { Age of } \\
\text { onset of } \\
\text { sweating }\end{array}$ & Scizures & $\begin{array}{l}\text { Pituitary } \\
\text { dwarfism }\end{array}$ \\
\hline Hines and Bannick $(1934)^{2}$ & $?$ & $\mathbf{M}$ & $12 \mathrm{yr}$ & - & - \\
\hline Hoffman and Pobirs (1942) & $?$ & $\mathbf{M}$ & $33 \mathrm{yr}$ & - & - \\
\hline Duff et al $(1961)^{4}$ & $?$ & $\mathbf{M}$ & $10 \mathrm{yr}$ & - & - \\
\hline Shapiro et al $(1969)^{5}$ & Agenesis of corpus callosum & $\mathrm{F}$ & $19 \mathrm{yr}$ & - & - \\
\hline Shapiro et al $(1969)^{5}$ & Agenesis of corpus callosum & $\mathbf{F}$ & $9 \mathrm{yr}$ & - & - \\
\hline Guihard et al $(1971)^{6}$ & Agenesis of corpus callosum & $\mathbf{M}$ & $1 \frac{1}{\mathrm{yr}}$ & + & + \\
\hline Fox et al $(1973)^{7}$ & Normal pneumoenceph & $\mathbf{F}$ & $46 \mathrm{yr}$ & - & - \\
\hline Noel et al $(1973)^{8}$ & Agenesis of corpus callosum & $\mathbf{M}$ & $25 \mathrm{yr}$ & - & - \\
\hline Thomas and Green $(1973)^{9}$ & Normal pneumoenceph. & $\mathbf{F}$ & $38 \mathrm{yr}$ & + & - \\
\hline Dutau et al $(1975)^{10}$ & Agenesis of corpus callosum & $\mathbf{M}$ & $6 \mathrm{mth}$ & + & - \\
\hline Sadowsky and Reeves $(1975)^{11}$ & Agenesis of corpus callosum & $\mathbf{M}$ & $18 \mathrm{yr}$ & - & - \\
\hline Carr-Locke and Millac (1977) ${ }^{12}$ & Agenesis of corpus callosum & $\mathbf{F}$ & $8 \mathrm{yr}$ & - & - \\
\hline Present case & Lipoma and agenesis of corpus callosum & $\mathbf{M}$ & $16 \mathrm{yr}$ & $:$ & - \\
\hline
\end{tabular}

The EEG during an episode of hypothermia showed diffuse symmetrical delta activity but between attacks there was only a slight excess of theta activity. Chest and skull radiographs, including coned lateral views of the pituitary fossa were normal. A CT brain scan showed a discrete area of fat density just to the right of the midline at the anterior end of the corpus callosum in the position normally occupied by the genu. There was evidence of agenesis of the corpus callosum (fig 3). A right carotid arteriogram showed the branches of the anterior
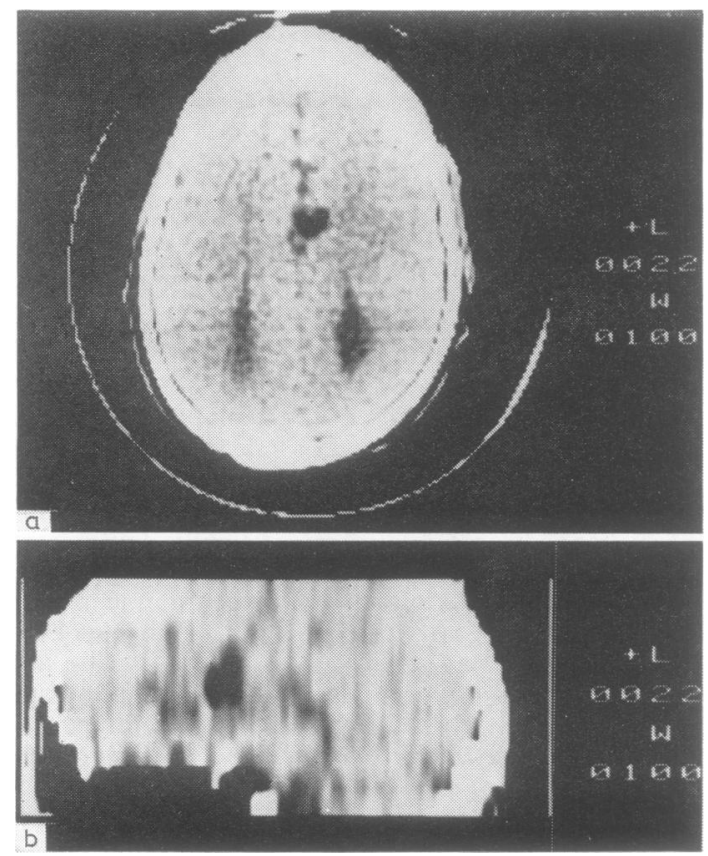

Fig 3 CT Brain scan (a) axial view (b) sagittal reconstruction. Area of fat density immediately to the right of the midline with widely separated and abnormal bodies of the lateral ventricles. The lipoma is shown to be in the position of the genu. cerebral complex to be more separate and straighter than normal and coursing superiorly in a diagonal radiating pattern towards the convexity. The pericallosal artery was shown to be very low in pusition and the internal cerebral vein high (fig. 4).

In attacks the patient was wrapped in blankets and the sweat removed frequently to prevent evaporation on the skin. The severe hyponatraemia was treated with normal saline given intravenously. To finally exclude any remediable lesion a neuro-surgical exploration of the area using a microsurgical technique was carried out via a coronal incision and restricted sagittal approach by division of the falx anteriorly. No true corpus callosum was identified and no mass lesion could be seen. The exploration was therefore terminated without biopsy or other procedure. Post-operatively there was no change and he continued to suffer frequent episodes of prolonged hypothermia.

\section{Discussion}

This patient is an example of a rare but increasingly recognised syndrome which is one cause of spontaneous hypothermia. Clinically it is characterised by attacks of profuse sweating and hypothermia often leading to stupor or coma. Investigation of the majority of patients reveals agenesis of the corpus callosum. This is the first recorded case of spontaneous hypothermia associated with a lipoma and agenesis of the corpus callosum. Lipoma of the corpus callosum is a rare tumour accounting for less than $0.05 \%$ of all brain tumours ${ }^{13}$ and in nearly $50 \%$ of cases there is associated agenesis of the corpus callosum. ${ }^{14}$ The tumour is asymptomatic in approximately $50 \%$ of cases 1516 but epilepsy, hemiplegia, dementia and headaches are common modes of presentation. ${ }^{13-16}$ There are no previously recorded cases of lipoma of the corpus callosum with periodic hypothermia but Zettner and Netsky ${ }^{14}$ record that diencephalic syndromes such as dystrophia adiposogenitalis, hypothermia and irregularities of menstruation may occur.

Agenesis of the corpus callosum is not believed to be the cause of the spontaneous hypothermia ${ }^{1217}$ 


\begin{tabular}{|c|c|c|c|c|c|c|}
\hline $\begin{array}{l}\text { Diabetes } \\
\text { insipidus }\end{array}$ & $\begin{array}{l}\text { Precocious } \\
\text { puberty }\end{array}$ & $\begin{array}{l}\text { Mental } \\
\text { retardation }\end{array}$ & Hypotonia & $\begin{array}{l}\text { Cranio-facial } \\
\text { dysmorphism }\end{array}$ & $\begin{array}{l}\text { Abnormal } \\
\text { external } \\
\text { genitalia }\end{array}$ & $\begin{array}{l}\text { Response to } \\
\text { anti-convulsants }\end{array}$ \\
\hline- & - & - & - & - & - & + \\
\hline - & - & - & - & - & - & + \\
\hline- & - & - & - & - & - & - \\
\hline- & - & - & - & - & - & - \\
\hline- & - & - & - & - & - & - \\
\hline$\therefore$ & $t$ & + & $\ldots$ & - & - & - \\
\hline- & - & - & - & - & - & - \\
\hline - & - & - & - & - & - & - \\
\hline- & - & - & - & - & - & - \\
\hline- & - & & - & - & - & - \\
\hline- & - & - & - & - & - & - \\
\hline- & - & - & - & - & - & - \\
\hline- & - & - & - & - & - & - \\
\hline
\end{tabular}

and similarly the lipoma in the present case seems unlikely to be the cause per se. Both lesions point to diffuse developmental abnormalities. ${ }^{18}$ The mechanism of attacks in this syndrome has never been satisfactorily explained. Previous authors have accepted these attacks as examples of diencephalic epilepsy ${ }^{5-812}$ as described by Penfield ${ }^{1}$ but there are good reasons for abandoning this term. ${ }^{911} 19$ Penfield in his detailed account emphasised the brief nature of his patient's attacks which lasted for 5-12 minutes.

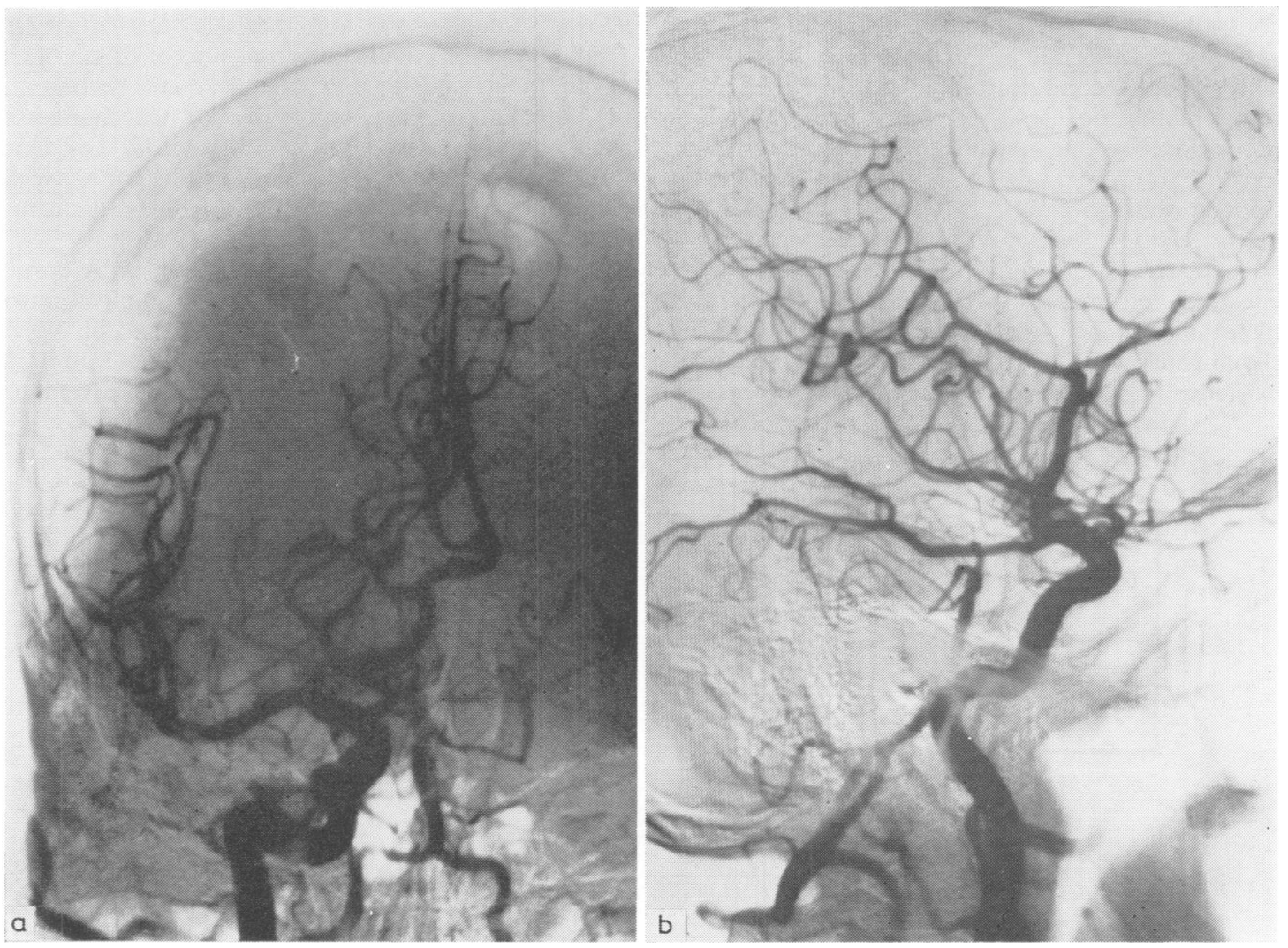

Fig 4 Right carotid arteriogram. Subtraction films. (a) Anteroposterior projection. (b) lateral projection The anterior cerebral artery complex is abnormal in position with the peri-callosal artery low and the branches of the peri-callosal are shown coursing in a diagonal fashion towards the convexity. 
The patient had raised intracranial pressure and all the features could be explained by acute intermittent hydrocephalus caused by a ball valve action of the intra-ventricular tumour. In contrast, patients such as the present case with spontaneous periodic hypothermia have attacks lasting hours or days and none have had raised intra-cranial pressure. ${ }^{212}$ Occurrence of seizures in three patients ${ }^{5910}$ has been cited as evidence of an epileptic mechanism for the sweating and hypothermia ${ }^{6}{ }^{12}$ but other factors such as the associated brain damage and severe hyponatraemia as in the present case, would in themselves be sufficient to produce seizures. Failure of anti-convulsants to control sweating and hypothermia in almost all the cases does not favour an epileptic mechanism.

Our patient's main disability is a disturbance of thermoregulation characterised by episodes of severe hypothermia due to increased heat loss from excessive sweating. The trouble is not due to inability to thermoregulate but stems from his abnormal "target" temperatures. Body temperature is normally controlled around $37^{\circ} \mathrm{C}$ but in this patient thermoregulation is aimed at achieving a lower temperature. The patient's condition could be described in the terms of the moveable set-point theory of thermoregulation, ${ }^{20}$ as one in which the set-point was usually lower than normal (about $35.5^{\circ} \mathrm{C}$ ) and which underwent episodes of reduction to an even lower level about $31 \cdot 0^{\circ} \mathrm{C}$ ). Reduction to this level was achieved by excessive sweating. This explanation postulates episodic and inappropriate changes in the intrahypothalamic neuronal equivalent of a reference signal generator. There is no direct evidence for the existence of such a neurone and it may be easier to explain our patient's disorder in terms of Bligh's ${ }^{21}$ recent updating of Vendrik's ${ }^{22}$ hypothesis, shown diagrammatically in fig 5 . In this model a set-point is produced by the inputs from hot and cold sensors, with the temperature-activity characteristics shown, acting on the reflex effectors both directly and through crossed inhibitory fibres. The final drive to the effector pathways to heat loss and heat production can be modulated by additional excitatory and inhibitory influences as shown which will produce changes in the apparent set-point.

The association between thermal sensation and the effector responses is obscure. Although the patient felt hot during the attacks, tests of thermal sensation gave normal results and it is unlikely that the excessive sweating was due to a change in the characteristics of the sensor neurones. A more likely explanation would be an increase in the off-line excitatory input to the heat loss neurone (fig 5). This would lower the resting set-point and if subject to episodes of further increases in activity, would cause periods of hypothermia due to increased sweating. An advantage of this hypothesis is that it increases the number of possible cerebral sites of origin of the excitatory impulses and extends them beyond the hypothalamus. Except possibly for the changes in the autonomic nervous system there is little evidence of damage to the hypothalamus of this patient while there are lesions in other regions, namely the frontal lobes and corpus callosum.

Spontaneous periodic hypothermia with corpus callosum abnormalities is a distinct clinical entity. In many reported cases hypothermia has been overlooked for several years and the symptoms attributed to some other medical or psychiatric

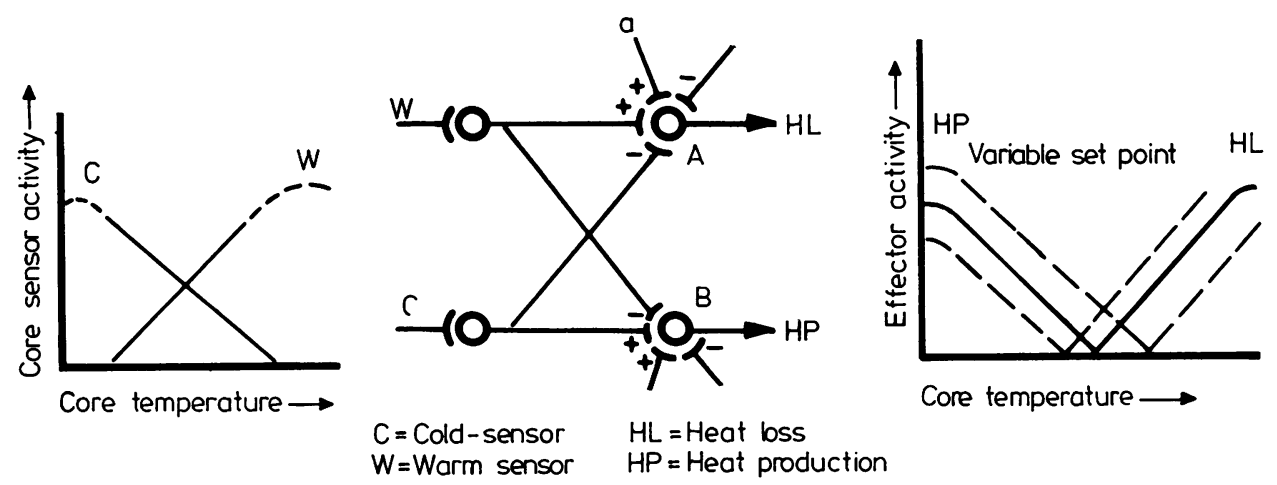

Fig 5 The diagram (after Bligh ${ }^{21}$ 1979) shows how a neuronal network of the layout shown centre with warm and cold sensors of the temperature activity relationships shown left will produce a set-point shown right. This set-point could be raised or lowered by excitatory and inhibitory inputs to neurones $A$ and $B$ by input from elsewhere in the central nervous system or from peripheral thermosensors. The situation in the present case could be explained by an increase in the excitatory input $a$. 
condition.41112 Routine use of a low reading thermometer would avoid this error. If the syndrome is recognised then a CT scan and tests of autonomic and thermoregulatory function are obligatory. Although no specific treatment exists, it may be that prompt symptomatic treatment consisting of heat conservation and sodium replacement would reduce the severity of episodes and prevent further cerebral damage which may be responsible for the progression noted in some cases. Total sympathectomy has proved effective in one case ${ }^{7}$ and this may be possible in similar cases with transient thermoregulatory abnormalities and absence of generalised autonomic dysfunction.

We thank the staff of the Departments of Medical Illustration, Salford Area Health Authority (T) and the University of Manchester, and Mrs D Ogden for preparation of the manuscript.

\section{References}

${ }^{1}$ Penfield W. Diencephalic Autonomic Epilepsy. Arch Neurol 1929;22:358-74.

${ }^{2}$ Hines EA, Bannick EG. Intermittent hypothermia with disabling hyperhidrosis: Report of a case with successful treatment. Proc Mayo Clinic 1934;9:705-8.

${ }^{3}$ Hoffman AM, Pobirs FW. Intermittent hypothermia with disabling hyperhidrosis. JAMA 1942;120:445-7.

4 Duff, RS, Farrant PC, Leveaux VM, Wray SM. Spontaneous periodic hypothermia. QJ Med $1961 ; 30: 329-38$.

${ }^{5}$ Shapiro WR, Williams GH, Plum F. Spontaneous recurrent hypothermia accompanying agenesis of the corpus callosum. Brain 1969;92:423-36.

${ }^{6}$ Guihard J, Velot-Lerou A, Poitrat C, Laloum D, L'Hirondel J. Hypothermie spontanee récidivante avec agénésie du corps calleux. Syndrome de Shapiro (nouvelle observation). Ann Pédiat 1971;
$18: 645-56$.

7 Fox RH, Wilkins DC, Bell JA et al. Spontaneous periodic hypothermia: Diencephalic epilepsy. $\mathrm{Br}$ Med J 1973;2:693-5.

${ }^{8}$ Noël P, Hubert JP, Ectors M, Franken L, FlamentDurand J. Agenesis of the corpus callosum associated with relapsing hypothermia. Brain 1973;96: 359-68.

9 Thomas DJ, Green ID. Periodic hypothermia. $\mathrm{Br}$ Med $J$ 1973;2:696-7.

${ }^{10}$ Dutau G, Carrière J-P, Rochiccioli P. Hypothermie spontanée récidivante avec hypoplasie du corps calleux. Pediatrie 1975;30:117-27.

${ }^{11}$ Sadowsky C, Reeves AG. Agenesis of the corpus callosum with hypothermia. Arch Neurol 1975;32 :774-6.

12 Carr-Locke D, Millac P. Diencephalic epilepsy in a patient with agenesis of the corpus callosum confirmed by computerised axial tomography. J Neurol Neurosurg Psychiatry 1977;40:808-14.

${ }^{13}$ Suemitsu T, Nakajima S, Kumajima K, Nihei K, Kamoshita S. Lipoma of the corpus callosum: Report of a case and review of the literature. Child's Brain 1979;5:476-83.

14 Zettner A, Netsky MG. Lipoma of the corpus callosum. J Neuropathol Exp Neurol 1960;19:305-19.

15 Wallace D. Lipoma of the corpus callosum. J Neurol Neurosurg Psychiatry 1976;39:1179-85.

${ }^{16}$ Tahmouresie A, Kroll G, Shucart W. Lipoma of the corpus callosum. Surg Neurol 1979;11:31-4.

17 Editorial. Episodic hypothermia. Lancet 1973;2:246-7.

${ }^{18}$ Ettlinger G. Agenesis of the corpus callosum. In: Vinken PJ, Bruyn GW, eds. Handbook of Clinical Neurology. Amsterdam: Elsevier/North Holland Biomedical Press, 1977;30:285-97.

19 Thomas DJ. Episodic hypothermia. Lancet 1973;22: 449.

${ }^{20}$ Hammel HT. Regulation of internal body temperature. Annu Rev Physiol 1968;30:641-710.

${ }^{21}$ Bligh J. The central neurology of mammalian thermoregulation. Neuroscience 1979;4:1213-36.

22 Vendrik AJH. The regulation of body temperature in man. Ned Tijdschr Geneeskd 1959;103:240-4. 